\title{
СУБЪЕКТНАЯ РАЦИОНАЛЬНОСТЬ ГУМАНИТАРНОГО ЗНАНИЯ
}

\begin{abstract}
А.И. Афанасьев
В различных сферах духовной деятельности реализуются два способа отношения к миру, водораздел между которыми можно провести по линии «теплого», субъективного, заинтересованного, личностного, интенционального отношения, в отличие от «холодного», объективного, незаинтересованного, безличностного, неинтенционального отношения [18, с. 10-13]. Потребность в различении двух способов отношения к миру возникла из осознания ограниченности «безсубъектной» картины мира [2], потребности «ценностно окрасить мир, наполнить его смыслом, сделать сопричастным человеку и общечеловеческой культуре» [10], необходимости диалогического, «встречающего» подхода к миру $[11$, с. 20] и т. д. «Холодное» и «теплое» отношения являются взаимодополнительными [18, с. 16-17], также как и монологический и диалогический, онтологический и аксиологический, объектный и субъектный и т. п. подходы. Они могут успешно применяться как к миру природы, представленному в естествознании, так и к человеческому миру, представленному в гуманитарном знании. Указанные два способа отношения или подхода можно представить как две разновидности рациональности. Тогда первый будет соответствовать субъектной, второй - объектной рациональности.

Целью статьи является выделение в гуманитарном знании субъектной рациональности и демонстрация ее отличия от объектной с учетом их взаимодополнительности и специфичности. Подобный ракурс исследования актуализируется тем обстоятельством, что проливает дополнительный свет на спорный вопрос, давно обсуждаемый в методологической литературе: научная рациональность едина ([14], [7],
\end{abstract}

Актуальні проблеми духовності

(Відп. ред.: Я.В. Шрамко)

Кривий Ріг (2007), 151-161 
[9], [1]) или существует особая гуманитарная рациональность, существенно отличающаяся от естественнонаучной ([15], [8], [3], [12], [13])?

Различение «теплого», субъективного, интенционального и, соответственно, «холодного», объективного, неинтенционального отношений позволяет разграничить в гуманитаристике две сферы научных знаний. С одной стороны, выделяется сфера строгой, традиционной науки с жесткими критериями научной рациональности, типичными научными теориями и парадигмами, объяснительными функциями, количественными оценками, «холодной» картиной мира, общенаучными идеалами и нормами, что обеспечивается объектным подходом, позволяющим там, где можно и нужно, исключить влияние субъекта-исследователя и исследуемого объекта-субъекта. Последнее отнюдь не отменяет объективный учет ответных реакций исследуемых объектовсубъектов, например, в психологии или социологии, возможной диалогичности, текстуальности, нарративности и т.д., но приоритет отдается истинности, а не понятности, отражательности, а не конструктивности, монологичности, а не диалогичности.

С другой стороны, выделяется вторая сфера гуманитаристики с нежесткими, слабыми критериями рациональности, нестрогими теориями, гибкими многослойными парадигмами, интерпретативными и описательно-конструктивными функциями, качественными оценками, «теплой» картиной мира, специфическими гуманитарными идеалами и нормами, что обеспечивается учетом заинтересованной позиции субъекта-исследователя, его конструктивными возможностями, полным учетом «возмущающего» влияния исследуемых объектов-субъектов, с акцентом на диалогичность, текстуальность, нарративность исследуемого материала. Приоритет отдается понятности, в частности взаимопониманию исследователей и исследуемых, а не истинности, а также конструктивности, а не отражательности, диалогичности, а не монологичности. Поскольку вторая сфера акцентирует внимание на субъекте, личности, она может быть названа субъектоведением, где «ведение», а не «-логия» подчеркивает отход от чрезмерно жестких применительно к данному материалу общенаучных стандартов, но полное соответствие рациональным нормам, с учетом того, что рациональное и научное - не одно и то же. В этой второй сфере гуманитаристики особенно отчетливо проявляются черты гуманитарного знания.

Различение двух сфер, а, следовательно, подходов, можно проиллюстрировать на примере из исторической науки. Объектный подход заключается в описании исторических событий в соответствии с документами, хрониками, хорошо проверенными, «объективными», сви- 
детельствами, сводящими к минимуму нарративный характер свидетельств или делающий его прозрачным. При этом, естественно, нельзя исключить влияния принятой исследователем картины мира, исторической исследовательской парадигмы и других конструктивных влияний субъекта-исследователя, но упор делается на объективные факты, возможно, только кажущиеся таковыми, и на интерсубъективный характер парадигмы, картины мира и т. п. Мнения, верования, предрассудки исторических персонажей, их понимание событий освещены фактами и современным пониманием той эпохи, которая известна исследователю, например, через парадигмы.

Субъектный, интенциональный подход в рамках субъектоведения подразумевает, прежде всего, описание интенций тех людей, которые жили в описываемый период, чтобы прошлая эпоха раскрылась через их намерения, чувства, верования, заблуждения, предрассудки, т. е. не только через то, что они делали, но и через то, о чем они думали, что чувствовали, во что верили. Не сбиться на объектный подход, остаться верным интенциональному подходу требует большого искусства и глубоких знаний, «вчувствования» в прошлую эпоху. Формально подобное историческое описание похоже на литературное, но, по сути, является научным, с соблюдением соответствующих требований рациональности.

Указанным двум сферам и подходам соответствуют объектная и субъектная рациональность.

Объектная рациональность подразумевает достаточно жесткие критерии: законы логики, четкие правила и образцы познавательных действий, каузальные схемы объяснения, научные законы, систематичность и др. требования науки. Перечень этот достаточно длинный и в перспективе уходит в бесконечность, поскольку идеалом такой рациональности является Абсолютный Разум. В этом смысле объектная рациональность тяготеет к универсальности, хотя в своем реальном функционировании рациональность далека от этого идеала. В то же время объектная рациональность не тождественна научной. С одной стороны, в научной рациональности присутствуют явные и неявные ценностные установки и личностные факторы, от чего объектная рациональность стремится избавиться. С другой стороны, объектная рациональность подразумевает некоторые вненаучные феномены духа, например, апелляцию к разуму в теологии, искусстве, обыденном сознании, здравом смысле и т. д., которым придается безсубъектный характер.

Объектная рациональность есть своеобразная установка сознания: 
стремление устранить влияние субъекта, представить рассматриваемое явление таким, каким оно есть «на самом деле». Эта рациональность может быть нацелена на любые феномены внешнего мира, человеческой деятельности, психики, культуры, но только под одним углом зрения - рассматривая их как особые предметы, которые подчиняются объективным законам. А там, где субъект не может сконструировать объективный предмет и представить его «естественную жизнь», заканчиваются притязания объектной рациональности, и проходит ее граница.

В объектной рациональности весьма затруднительно выявить специфику гуманитарного знания, и тезисы о единой рациональности, единых критериях научности, тождестве рациональности и научности и т. п. здесь вполне уместны. Это и служило основанием для отрицания особых методов и познавательных средств в гуманитарных науках, для ориентации на естественнонаучные идеалы, к которым гуманитарные науки якобы должны стремиться, чтобы конституироваться в качестве полноценных наук. Подобная ориентация принесла свои положительные плоды. Ряд социологических, исторических, лингвистических и др. дисциплин соответствует самым строгим критериям научности.

В то же время духовная активность субъекта не всегда ориентирована идеалами строгого научного познания, внешне-предметные действия и их объективированные результаты не являются только опредмечиванием знаний. Вместо установки сознания на устранение влияния субъекта, может иметь место противоположная установка - на включение субъекта в рассматриваемое явление или просто не быть таких установок. Подобные феномены духовной и практической деятельности вряд ли попадают автоматически в разряд иррационального, хотя под единый идеал рациональности их невозможно подвести. Но в некотором смысле рациональность может хотя бы потенциально покрывать многие, если не все формы духовной активности, в том числе вненаучные.

Во-первых, последние могут быть рационально описаны и объяснены в тех или иных теориях. Во-вторых, они, как правило, соответствуют некоторым культурным или социальным нормам, природа которых, в конечном счете, рациональна. Даже гнев или иные, на первый взгляд, абсолютно иррациональные эмоциональные всплески духовной деятельности индивидов или групп осуществляются в некоторых культурных нормах и уж, во всяком случае, описываются и объясняются определенным рациональным образом. В-третьих, сами индивиды, осмысливая свои многообразные духовные проявления на сеансах пси- 
хотерапевта, в дневниках и автобиографических очерках, в письмах и устных повествованиях, облекают их в определенные рациональные формы. Все это порой не относят к научной рациональности, поскольку последняя связывается с объектной рациональностью, требованиям которой вышеназванные проявления духовности действительно не соответствуют. Однако в рамки субъектной рациональности они укладываются.

Часто рациональность неправомерно соотносят лишь с познавательной деятельностью человека. Но, с одной стороны, поскольку она органически вплетена во все способы духовной деятельности человека, то все они должны считаться в той или иной мере рациональными. С другой стороны, если мы выделяем познавательную составляющую, особенно науку как ее образец, то тогда иррациональным будем вынуждены назвать огромный массив духовно-практического освоения миpa, что не соответствует образу homo sapiens. Поэтому логичнее допустить рациональность не только внутри, но и вне познавательной сферы деятельности. Такую рациональность также следует отнести к субъектной рациональности. Она лишь частично представлена в научнотеоретическом способе духовного освоения и познания мира и самого человека, где доминирует объектная рациональность. Между прочим, философия, являющая собой специфический вид духовной деятельности, не совпадающий полностью с наукой, сочетает в себе объектную и субъектную рациональность.

Субъектная рациональность превалирует в художественном, религиозном, моральном и других подходах к миру. Вряд ли можно сказать, что художественный образ абсолютно нерационален, особенно по форме функционирования, когда он продуманно воплощается на полотне или в литературном тексте. Если по происхождению образ, мнение, верование кажутся иррациональными, то и многое в науке, если быть последовательным, надо считать иррациональным, хотя бы по способу появления в голове ученого. Вообще, современный человек не может обосновать весь объем информации, с которой взаимодействует, и вынужден многое принимать на веру, на что обращает внимание Ю. Хабермас, называя это явление «новой непрозрачностью» и рассматривая его как существенный отход от просвещенческого разума. Однако проще такой феномен соотнести с субъектной рациональностью. Тем более - по способу функционирования в культуре - и понятия, и верования, и образы вполне рациональны, так как подчиняются определенным нормам, обосновываются. То же касается религиозных догм, мыслительные операции с которыми в средневековых диспутах 
оттачивали критерии рациональности.

Субъектная рациональность многообразна, охватывает довольно пестрый спектр духовной сферы деятельности: от науки до обыденности, от уникального до всеобщего, от знания до ценности, от обоснования до верования. Иррациональными их иногда называют лишь с позиций жесткой научной рациональности. Именно констатация феноменов субъектной рациональности служит поводом для отрицания единой рациональности, для противопоставления гуманитарной сферы духа естественнонаучной, для поиска особых, специфических методов и средств гуманитаристики.

Не претендуя на полноту описания, отнесем к субъектной рациональности пять наиболее часто встречающихся проявлений духовной деятельности, расположенных в порядке удаления от объектной рациональности.

Во-первых, имеется в виду фиксация нетипичного. В ряде случаев невозможно абстрагироваться от места, времени, ситуации и прочих специфичностей, «единичностей» при изучении человека, его деятельности или мышления и выйти на абстрактно-рациональные, идеальные конструкты. Это встречается в исторических исследованиях, когда существенным оказывается изучение традиций данной семьи, отдельной фабрики или поместья, что нередко ближе к литературе, чем к науке, но без чего не будет сколько-нибудь полного представления изучаемой эпохи. Аналогичные примеры можно обнаружить в психологии при нестандартном поведении индивида или группы, в литературоведении и художественной критике, сталкивающихся с уникальным талантом и т. Д.

Во-вторых, субъектная рациональность предполагает учет личностного и вообще субъективного при ссылке на разумность. Если для объектной рациональности степень объективности гуманитарного знания, как и вообще всякого знания, прямо пропорциональна степени его удаленности от субъекта, то для субъектной рациональности мера личностной вовлеченности прямо и непосредственно коррелирует с мерой объективности и точности гуманитарного знания, например, если целью исследования является точная характеристика исторического персонажа или деятеля искусства. Кроме того, установлено, что субъективное понимание исторических событий или социальных фактов участвует в построении самих фактов, в частности, в различных формах нарратива [5, с.33] и существенно при анализе любого текста [6, с. 459-460]. K тому же субъектная рациональность предполагает учет изменений исследуемого субъекта в ходе диалога с субъектом-ис- 
следователем [4, с. 383]. Очевидно, что стандарты жесткой объектной рациональности тут не работают.

В-третьих, к субъектной рациональности можно отнести ценностные представления, играющие явную роль, например, в процессе художественного освоения действительности и не столь явную роль в научном творчестве. В содержании сознания всегда присутствуют сплав знаний и ценностей, особенно мировоззренческих. Ценностномировоззренческие представления и оценочные суждения ученого не входят непосредственно в состав порождаемого знания, они остаются в контексте открытия, который опускается при экспликации или трансляции научного знания. Можно вспомнить ссылки Ньютона на Бога, которые не вошли в формулировку его законов, или дарвиновский термин «борьба за существование», ненужный в его теории и лишь дублирующий термин «естественный отбор».

В этом ряду можно упомянуть важнейшую ценность науки, как правило, не осознаваемую учеными: особую структуру научных текстов. Они говорят как бы от имени природы, благодаря лингвистическим структурам, делающим научные тексты убедительными. Так, «Оптика» Ньютона использовала принципы построения и терминологию работ Эвклида, заимствуя их риторическую силу, хотя содержала только описания экспериментов и их результатов $[16$, с. 53$]$. С точки зрения объектной рациональности вышеперечисленные ценности выглядят иррациональными, по крайней мере, часто не осознаются исследователями. Однако их рациональная природа проявляется при сознательном их использовании и при прояснении их роли в науке. В этом плане гуманитарному исследованию на предмет обнаружения субъектной рациональности могут подвергаться и естественнонаучные тексты.

Ценностные представления преобладают в жизнеучениях, среди которых значатся самые разнообразные: философские, теологические, обыденные, - несущие в себе ту или иную прагматическую интенцию. Хотя некоторые из них можно представить в виде рационализованных этических концепций, похожих на теории и обозначенные как истинные или ложные, все же главное в них - ценностные компоненты, которые нельзя свести к строгому научному знанию. Но и вывести их вообще за рамки рациональности невозможно. Им принадлежит огромная упорядочивающая и смыслообразующая роль, особенно в традиционных обществах. Отцовские наставления играли роль, сходную не только с ролью юридических законов, но и с ролью фундаментальных законов природы, не выполнять которые нельзя. Соответственно деятель- 
ность в русле подобных установок является рациональной. Очевидно, что такая рациональность отличается от научной, ибо может не осознавать законов логики и даже порой не следовать им, не отличаться систематичностью или не соблюдать других отдельных требований жесткой объектной рациональности. В то же время здесь обнаруживается, к примеру, ясность, воспроизводимость и общеприемлемость определенных образцов деятельности, общее согласие относительно правил поведения, что соответствует, в частности, операциональной и нормативной интерсубъективности как формам проявления рациональности [17, с. $220-222]$.

В-четвертых, субъектная рациональность охватывает индивидуальные мнения, впечатления, особенно злободневные, в журналистике, литературной, художественной, музыкальной критике. Например, в литературоведении можно различать исследования более близкие к науке и более отдаленные от нее. Первые тяготеют к объектной рациональности, если там соблюдаются критерии объективности, экспериментальной проверки, воспроизводимости опыта и др. Вторые - к субъектной, если там преобладает не позиция ученого, а мнение профессионала, просто делящегося впечатлениями на злободневную тему, не заботясь об их соответствии Абсолютному Разуму, Вечной Истине, Полной Объективности. Часто идеальные конструкции трудно или невозможно построить из-за такой особенности гуманитарного знания, как большая сложность изучаемых объектов по сравнению с естественнонаучными, поэтому «впечатления» оказываются единственно возможными, а то и более точными или более понятными, чем громоздкие и противоречивые теоретические конструкции.

В данном своем проявлении субъектная рациональность тесно переплетена с чувствами, переживаниями, соответствующими внутренней позиции субъекта и эмоционально окрашивающими его размышления и вообще интеллектуальную деятельность. В частности, во многом из-за этого в гуманитарных исследованиях обнаруживается более сложная, чем в естествознании, ситуация наблюдения: очень часто она оказывается той внутренней позицией, от которой трудно, а порой невозможно, отвлечься. Требуется дистанцирование, как временное, так и пространственное. Последнее обстоятельство позволяет понять, почему далекую от нас культурную ситуацию нам легче освоить, чем недавнюю или современную. Здесь важны как минимум два момента. Во-первых, современность вызывает больше эмоций, переживаний, больше задевает непосредственные сиюминутные интересы. Во-вторых, далекое прошлое легче упростить, абстрагировавшись от несу- 
щественного, иногда только кажущегося таковым. В современной ситуации отделить существенное от несущественного, эмоциональное от рационального значительно труднее.

Хотя в общем виде субъектная, как и объектная, рациональность понимается как апелляция к доводам рассудка, а не к эмоциям, и к интерсубъективным положениям, а не к личным, особенно непрофессиональным, мнениям, но в конкретных социокультурных ситуациях личные мнения могут иметь общезначимый контекст, а чувства и эмоции - вписываться в некоторые культурные нормы, в особенности, когда провоцируются соответствующей логической аргументацией. Так возникают праведный гнев, истинная скорбь, высшие чувства, которые не покрываются ни рамками иррациональности, ни рамками объектной рациональности.

В-пятых, субъектная рациональность соотносится с представлениями, включающими социально-политическую, нравственно-эстетическую и др. заинтересованность субъекта: групповую, национальную, общечеловеческую. Примером могут служить идеологии, представляющие свой частный интерес как общезначимый. Общезначимой она и выглядит для сторонников данной идеологии. Идеологии, в частности, соответствуют всем пяти, выделенных К. Хюбнером [17, с. 220$222]$, основным формам интерсубъективности, в которых проявляет себя рациональность. Действительно, в любой идеологической системе налицо ясность и общая приемлемость понятий и построенных из них суждений, т.е. семантическая интерсубъективность. Имеет место обоснованность чьих-либо высказываний эмпирическими фактами, бесспорными для всех участников дискуссии, т. е. эмпирическая интерсубъективность. Обнаруживается обоснованность высказываний логическими выводами, т.е. логическая интерсубъективность. Бросается в глаза ясность, воспроизводимость и общеприемлемость определенных образцов деятельности, т.е. операциональная интерсубъективность. Наконец, присутствует ясность, понятность и общее согласие относительно правил поведения, т. е. нормативная интерсубъективность. Кстати, это дает основания считать идеологию ненаучной по одним признакам и одновременно научной - по другим.

Выделение субъектной рациональности, и ее отличие от объектной, позволяет расширить сферу рациональных оснований гуманитарного знания, определить специфику гуманитарного познания, в котором решающую роль играет субъектная рациональность, обнаружить способность гуманитаристики создавать, с одной стороны, строго научное знание по типу естественнонаучного на основе объектной рациональ- 
ности, с другой-менее строгое знание на основе субъектной рациональности.

\section{1 Литература}

[1] Автономова Н.С. Рациональность: наука, философия, жизнь // Рациональность как предмет философского исследования. - М.: ИФРАН, 1995.- С. 47-75.

[2] Афанасъев А.И. Картина мира гуманитарных наук // Актуальні проблеми духовності.-Зб. наукових праць / Відп.ред. Я.В.Шрамко. - Вип. 7. - Кривий Ріг: Видавничий дім, 2006. C. $191-200$

[3] Башляр Г. Новый рационализм. - М.: Прогресс, 1987.

[4] Бахтин M.М. Эстетика словесного творчества. - М.: Искусство, 1979.

[5] Брокмейер Й., Харре Р. Нарратив: проблемы и обещания одной альтернативной парадигмы. // Вопросы философии. - 2000. № 3.- C. 29-42.

[6] Гадамер Г.-Г. Істина і метод. Т. 1. - К.: Юніверс, 2000.

[7] Гемпель K. Мотивы и «охватывающие» законы в историческом объяснении // Философия и методология истории.-М.: Прогресс, 1977.- С. 72-93.

[8] Гири K. Насыщенное описание: в поисках интерпретативной теории культуры // Антология исследований культуры. Том 1: Интерпретации культуры. - СПб: Университетская книга, 1997.C. 170-199.

[9] Дрей У. Еще раз к вопросу об объяснении действий людей в исторической науке // Философия и методология истории. - М.: Прогресc, 1977.- С. 37-71.

[10] Илъин B.В. Теория познания. Введение. Общие проблемы. - М.: Изд-во МГУ, 1993.

[11] Лифинцева Т.П. Философия диалога Мартина Бубера. - М.: Издво ИФРАН, 1999. 
[12] Микешина Л.А., Опенков М.Ю. Новые образы познания и реальности. - М.: РОССПЭН, 1997.

[13] Никитин Е.П. Спецрациональность // Исторические типы рациональности. - Т. 1. - М.: ИФРАН, 1995.-С. 56-70.

[14] Поппер К. Нищета историцизма //Вопросы философии.-1992.№ 10.- C. 29-58.

[15] Хабермас Ю. Моральное сознание и коммуникативное действие. СПб.: Университетская книга, 2000.

[16] Харре P. Социальная эпистемология: передача знания посредством речи // Вопросы философии. - 1992. - № 9.- С. 49-60.

[17] Хюбнер К. Истина мифа. - М.: ИФРАН, 1996.

[18] Цофнас А.Ю. Комплементарность мировоззрения и миропонимания // Философская и социологическая мысль. - 1995. - № 1-2.C. 5-22. 